\section{Gastrectomy is a Risk Factor for Alcoholism}

To the Editor: Dear Sir. Four hundred and thirty-seven alcoholics (alcohol dependence syndrome, 406 male and 31 female), who were admitted to the Alcohol Center in Kohdo Mental Hospital to take part in 12 weeks of abstinence training by their own will, were evaluated for a history of gastrectomy. Their mean age was $51.2 \pm 11.5$ years (male $51.5 \pm 11.4$, female $46.7 \pm 11.2$ ). Seventy-two out of 437 patients, $16.5 \%$ [67 out of 406 males (16.5\%) and 5 out of 31 females (16.2\%)], had a history of gastrectomy, which was confirmed by an upper gastrointestinal series performed at the center. In $17 \mathrm{pa}-$ tients ( 15 male and 2 female), the onset of alcoholism preceded gastrectomy. The other 55 patients ( 52 male and 3 female) had developed alcoholism after gastrectomy. The average period between gastrectomy and the onset of alcoholism was $6.8 \pm 7.9$ years (ranging from immediately after operation to 30 years), with 44 patients developing alcoholism within 3 years of gastrectomy The reasons for gastrectomy were investigated by patient's declaration (not by charts of other hospitals). The reasons for gastrectomy prior to the onset of alcoholism were as follows: gastric ulcer 32 ( 29 male and 3 female), duodenal ulcer 11 (all male), gastric cancer 3 (all male), esophageal cancer 1 (male) and unknown reason 8 (all male). Gastrectomy was performed due to 7 gastric ulcers ( 6 males and 1 female), 1 duodenal ulcer (male), 5 gastric cancers (all male), 1 esophageal cancer (male), and 3 for unknown reason ( 2 males and 1 female) after the onset of alcoholism.

Yokoyama et al reported that gastrectomy enhances the vulnerability to the development of alcoholism in a group of patients in Japan (1). They reported a higher incidence of history of gastrectomy in male alcoholics $(9.7 \%, 47 / 486)$ than in male employees of two large companies $(0.8 \%, 36 / 4,381 ; 0.6 \%, 6 /$ 950 ), and the majority of gastrectomized patients (30/47) had no history of problem drinking before gastrectomy. We observed a higher percentage of gastrectomy in alcoholics (16.5\%) and a high incidence of development of alcoholism after gastrectomy ( 55 out of 72 gastrectomized alcoholics). From the standpoint of surgeons, the development of alcoholism was also reported as a cause of increased mortality after the gastrectomy (2). The mechanism for the development of post-gastrectomy alcoholism may involve the loss of gastric first pass metabolism of ethanol followed by a quick passage of ethanol into the small intestine, resulting in massive entry of ethanol into systemic circulation and the induction of alcohol tolerance and dependence $(3,4)$. Gastrectomy should be considered to be a risk factor for alcoholism, and patients with gastrectomy should be closely monitored. Since many health care workers (surgeons, internists, general practitioners, psychiatrists, social workers, etc.) will encounter patients after gastrectomy, we believe the concept that "gastrectomy induces alcoholism" should be widely disseminated. This information should permit health care workers to develop treatment and education strategies that will prevent the development of alcoholism in patients with gastrectomy.

$$
\text { Satoshi Ito*, Teiji IzUmi** and Masaaki AraKaWA* }
$$

*The Department of Medicine (II), Niigata University School of Medicine, Asahimachi 1-757, Niigata 951-8510 and **Kohdo Mental Hospital, 15-1, Yuraku 1-chome, Niigata 950-0012

\section{References}

1) Yokoyama A, Takagi $\mathrm{T}$, Ishii $\mathrm{H}$, et al. Gastrectomy enhances vulnerability to the development of alcoholism. Alcohol 12: 213-216, 1995.

2) Lundegardh G, Helmick C, Zack M, Adami HO. Mortality among patients with partial gastrectomy for benign ulcer disease. Dig Dis Sci 39: 340-346, 1994.

3) Caballeria J, Frezza M, Hernandez-Munoz R, et al. Gastric origin of the first-pass metabolism of ethanol in humans: effect of gastrectomy. Gastroenterology 97: 1205-1209, 1989.

4) Elmslie RG, Davis RA, White TT. Absorption of alcohol after gastrectomy. Surg Gynecol Obstet 119: 1256-1258, 1964. 